\title{
DEVELOPMENT OF 3D SIMULATION-BASED M\&S EDUCATION PLATFORM FOR SMART LEARNING
}

\author{
SeonYong Hong, Korea Advanced Institute of Science and Technology,gosyhong@kaist.ac.kr \\ YongHyun Hwang, University of California Irvine, freeaion@gmail.com
}

\begin{abstract}
As the research on convergence of knowledge is being progressed, STEAM creativity education and training become important. With the rapid advancement in the information and communication technologies, the computer literacy training actively deploys variety of smart devices and three-dimensional educational content. In this paper, $3 D$ modeling and simulation platform for smart learning is proposed. The proposed $3 D M \& S$ education platform can improve creative thinking, application of convergence of knowledge, and various problem-solving skills. This current research aims to be foundations for the next generation of smart education curriculum development.
\end{abstract}

Keywords: Smart Learning, Education Platform, 3D Simulation and Creative Problem Solving

\section{INTRODUCTION}

With ever increasing importance of creativity education and smart curriculum, there have been active researches on smart learning throughout smart training strategy. One of the most important directions in smart learning implies creativity education. This has paved a new way to AR (Augmented Reality) based or 3D contents based education using smart devices as important didactics. Such a didactics requires convergent way of thinking and creativity development, which would change a whole paradigm in education. The creativity education enables creative design and brain development for new idea, imagination, and CPS (creative problem-solving). This makes the creativity education be a fundamental for an applied education such as STEAM education [1,2]. Figure 1 explains STEAM pyramid by Georgette Yakman [3]. STEAM is proving successful in schools all around the world to better teach academic and life skills in a standards-backed, realistic-based, personally relevant exploratory learning environment. The STEAM structure explains how all the divisions of education and life work together, therefore it offers a formal place in the STEM structure for the Language Arts, Social Studies, and the purposeful integration of the exploratory subjects including; the Arts, Music, CTE and Physical Education divisions of public education [4]. Shifting to a STEAM perspective means understanding learning contextually; not only in terms of having a framework that illustrates where the subjects overlap, but also in providing a living and adaptable learning structure for everchanging personal and unpredictable global development [5]. The current trends in education that are related to the discipline include areas of integration, academic accountability, and a variety of literacies [6].

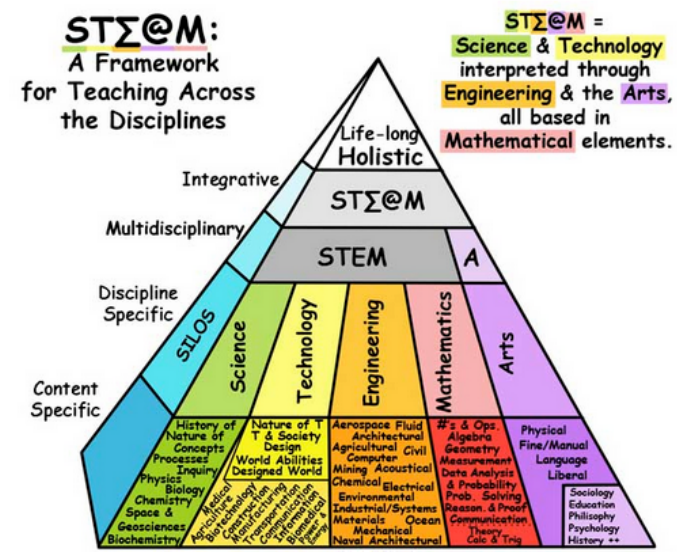

Figure 1. STEAM pyramid by Georgette Yakman 


\section{Issues in Information Systems \\ Volume 14, Issue 2, pp.225-232, 2013}

The smart learning gets possible by comprehensive paradigm shifts in IT technologies, media technologies, teaching-learning model, and social networking platform. Most of all, IT technologies allow a student to access any information anytime and anywhere. Especially, cloud computing is an enabling technology providing various contents for the smart learning along with learner's group intelligence and environment for social learning [7].

Digital textbook by media technologies is another cornerstone for the shift. With the digital textbook, a student can entertain multimedia data, which is far efficient and convenient in learning, compared to a paper textbook. The importance of appearance in the design of digital textbooks was highlighted in the Visual Book experiment, which studied the application of the paper book metaphor to the design and production of electronic textbooks. The digital textbook found that users received electronic texts that closely resemble their paper counterparts in terms of visual components such as size, quality and design positively. Readers felt familiar with the representation of the book on screen and were able to rely on their experience with paper books to interact with the electronic textbook [8]. A good example is AR that allows more interactive and live learning. One drawback of AR is it requires special equipment or induces lots of costs in creating good contents [9]. This research gives a brief insight into the potential and challenges of using collaborative Augmented Reality in education within the greater context of immersive virtual learning environments [10]. For now, this is limiting big potential of AR in the smart learning.

In addition, the paradigm shift comes from a change in teaching-learning model as well. The model is changing from teacher-centric to learner-oriented. In the learner-oriented model, learner's tendency and learning method are analyzed to suggest a learning model tailored to a learner. Based on the analysis, group study, mentor-mentee learning and peer-learning can be considered, where the effectiveness of learning is maximized by learner's selfmotivation and experienced members.

Finally, social network platform contributes to the comprehensive paradigm shift. Web 2.0 leads innovation and changes which gives a birth to Education 2.0. The core of the Education 2.0 lies in the fact that learners communicate with each other and produce knowledge based on openness, share, and participation [11]. Major universities have shared class materials and made them available to a public. This is called OER (Open Educational Resource). The examples are MIT's Open Course Ware, Yale's Open Yale Course, and University of California Television $[12,13]$. OER mainly focuses on information delivery rather than an active interaction from/to a learner. The learner cannot apply one's experience or creativity directly to OER to learn by exercise. To address this limitation, this paper provides next-generation education platform for smart creativity learning, which allows a learner to absorb knowledge and apply them quickly throughout direct modeling and simulation.

This paper is organized as follows. In section 2, case studies and education status utilizing simulation are discussed as related works. Section 3 introduces 3D M\&S education platform design and a case of learning method-taking advantage of the platform. Finally, a result, conclusion and future works is presented.

\section{RELATED WORKS}

Smart learning makes use of smart devices. The devices realize anywhere and anytime access to educational contents, which opens a new chapter for learning process. The smart learning with smart devices is efficient, but the current smart learning has limitation where the learning is one-way and not that interactive. To mitigate the limitation and provide more interaction, simulation-based learning method is proposed. One of the approaches for the simulation based learning method makes use of a virtual robot. The virtual robot is simulation software to simulate a behavior and operation of an actual robot. To give an example, MSRDS (Microsoft Robotics Developer Studio) is robot platform software virtualizing physical robot. Microsoft Robotics Developer Studio was publicly released in December 2006 with the explicit goal of providing an industry software standard for robot control. To become a viable standard, several technical challenges needed to be solved. MSRDS is a Windows-based system focused on facilitating the creation of robotics applications. It is built upon a lightweight service-oriented programming model that makes simple the development of asynchronous, state-driven applications. Its environment enables users for interacting and controlling robots with different programming languages [14]. Moreover, its platform provides a common programming framework that enables code and skills transfer including the integration of external applications. Intelligent robot development platform provides tools to implement virtual robot and define 


\section{Issues in Information Systems \\ Volume 14, Issue 2, pp.225-232, 2013}

environment where the robot is implemented and working [15]. Another example is Simbad. Figure 2 shows the interface of Simbad platform providing 3D robot simulation engine and tools based on JAVA [16].
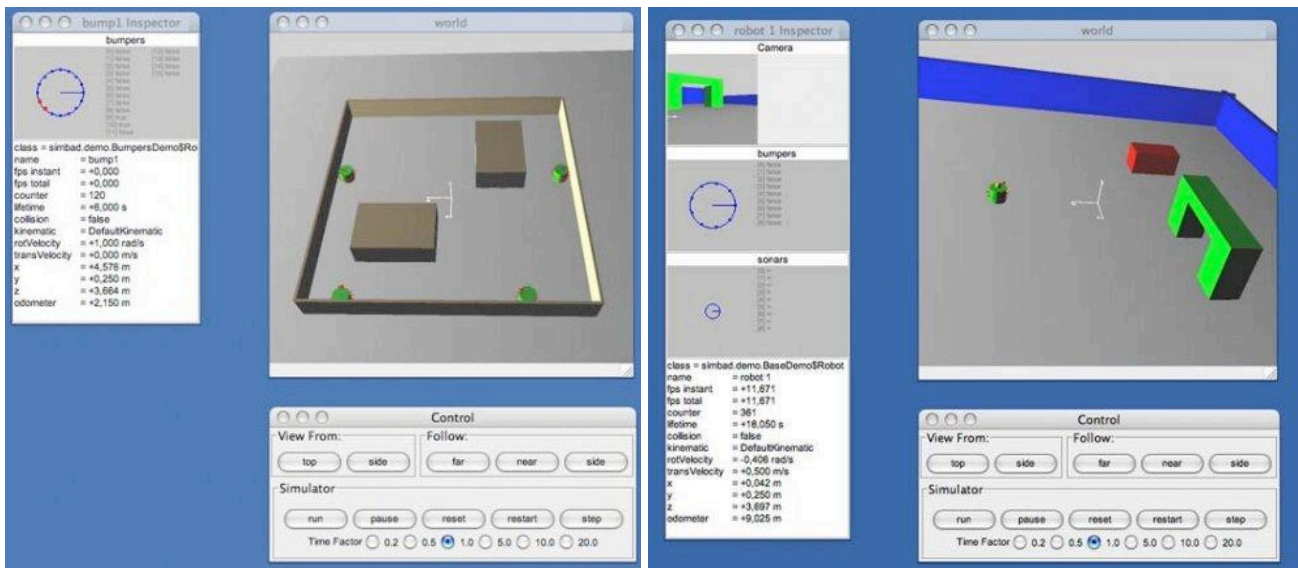

Figure 2. Simbad Platform Interface

Simbad is an open source Java $3 \mathrm{~d}$ robot simulator for scientific and educational purposes. Even though Simbad supports Mac, Windows, and Linux environment and can be extensible by new API, it provides limited set of simulation environments [17]. Because of this, it is hard to expect great improvement in learner's creativity development or problem solving technique. Other examples cover TeamBots and Eyesym. TeamBots is able to simulate several robots simultaneously. This is possible throughout its central control system. The issue with the TeamBots is that it is not for learning. Rather than for learning purpose, it focuses on the actual robot development. Figure 3 shows the robot soccer simulation interface [18].

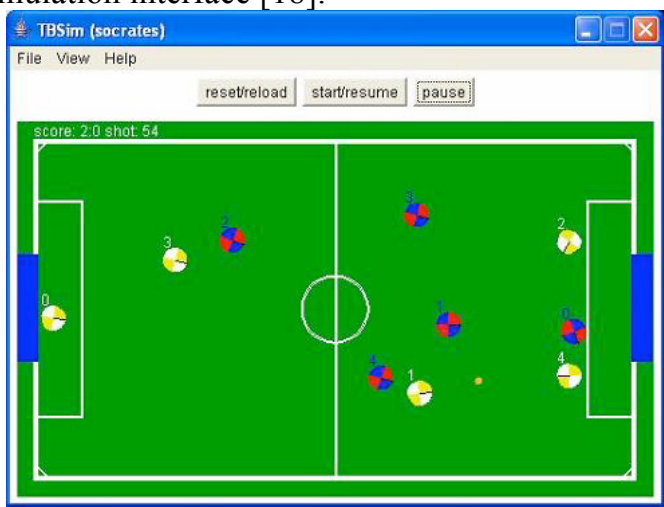

Figure 3. TeamBots platform

Software robot has great potential and merits for learner-oriented education. To fully maximize the potential and merits, this paper proposes a software platform to perform smart convergent education based on robot simulation environment, which effectively realizes smart learning. The proposed platform is named as 3D M\&S. It provides robot simulation environment and can sync software robot with an actual robot, which can dramatically reduce robot development cost and time.

\section{DESIGN OF 3D M\&S EDUCATION PLATFORM}

3D M\&S education platform consists of a) model design part and b) simulation engine. a) implements GUI based IDE (Integrated Development Environment) to provide flexible model design for learner's creative idea. b) interprets component based VPL (Visual Program Language) for simulation. Figure 4 shows each module in the 3D M\&S education platform. 


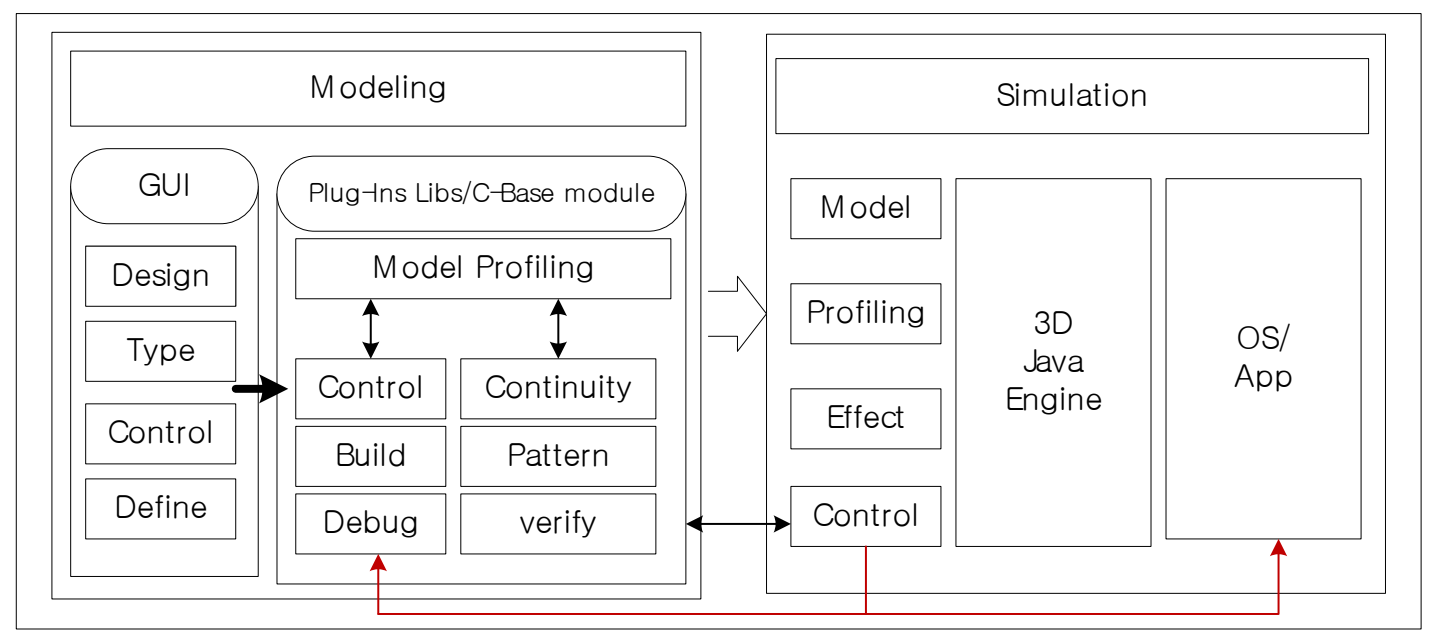

Figure 4. 3D M\&S platform environment

Based on robot technology, model design and simulation process on 3D M\&S platform covers science, mathematics, and art for smart learning. The property of smart learning is a) model design is based on science, b) program is implemented using mathematical algorithm, and c) designed model is shaped artistically. a) and b) can improve creative thinking and problem solving skills while c) is good for artistic sense. SMART education designs a robot based on scientific principles, programs it with mathematical algorithm, and artistically shape it. When implementing a robot, creative thinking and problem solving technique plays a critical role. Therefore, prior to an education, it is important to design teach-learning model after defining what is scientific thinking ability, mathematical application, and artistic design. In SMART teach-learning model, basic tasks are designed for all students in a scientific school [19].

\section{M\&S Learning Process}

M\&S Leaners to use their ideas through a variety of modeling are to assemble the parts. And modeling program for the robot is built on VPL. The simulation program written to run directly from the WEB can be seen. The learning process using 3D M\&S platform consists of five steps. The steps are as follows.

[Step 1] survey activity: understand a problem and imagine a robot to resolve it

[Step 2] design and modeling: design and model a robot considering requirements.

[Step 3] model development: implement a robot using modeling tool

[Step 4] programming: implement a program to describe major functions of the robot

[Step 5] simulation and experiment: perform experiments throughout robot simulation

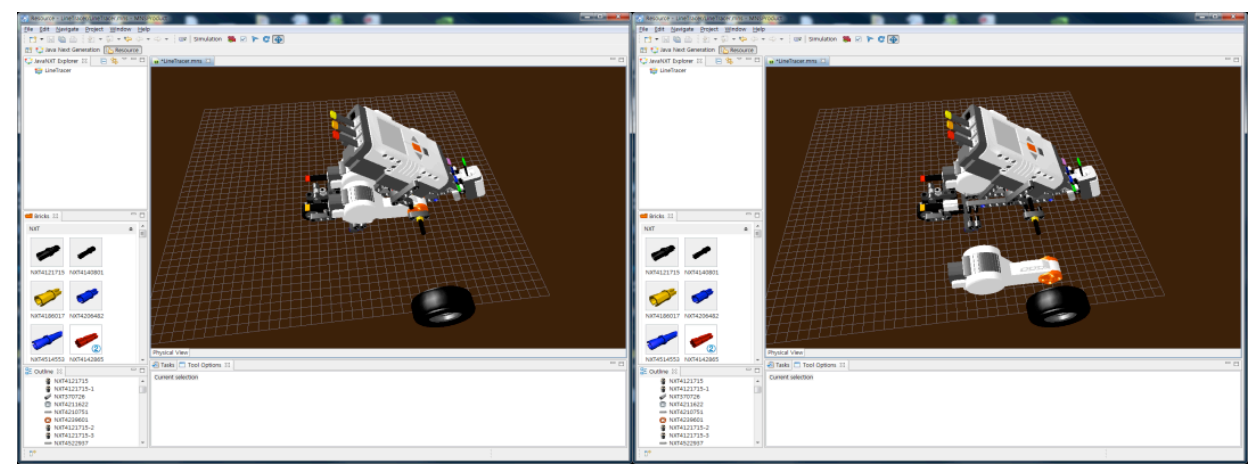

Figure 5. Lego's NXT Mind Storm Robot Modeling and Assembly Process 


\section{Issues in Information Systems \\ Volume 14, Issue 2, pp.225-232, 2013}

Learners drag and drop on the left side of the robot parts easily can be assembled on the main screen. In this paper, by utilizing part of the educational robot was implemented. Depending on the parts they need to add, delete, and modify the two is possible. Figure 5 shows Lego's NXT mind storm robot modeling and its assembly process using the M\&S platform. If a learner performs all the five steps using actual hardware, large costs should be paid. In addition to the cost issue, number of possible hardware components would be limited as well. According to the research by Fagin and Merkle [20], a learner is less satisfied with the education using a robot because feasible models that a learner can make are limited and an experiment is not easy.
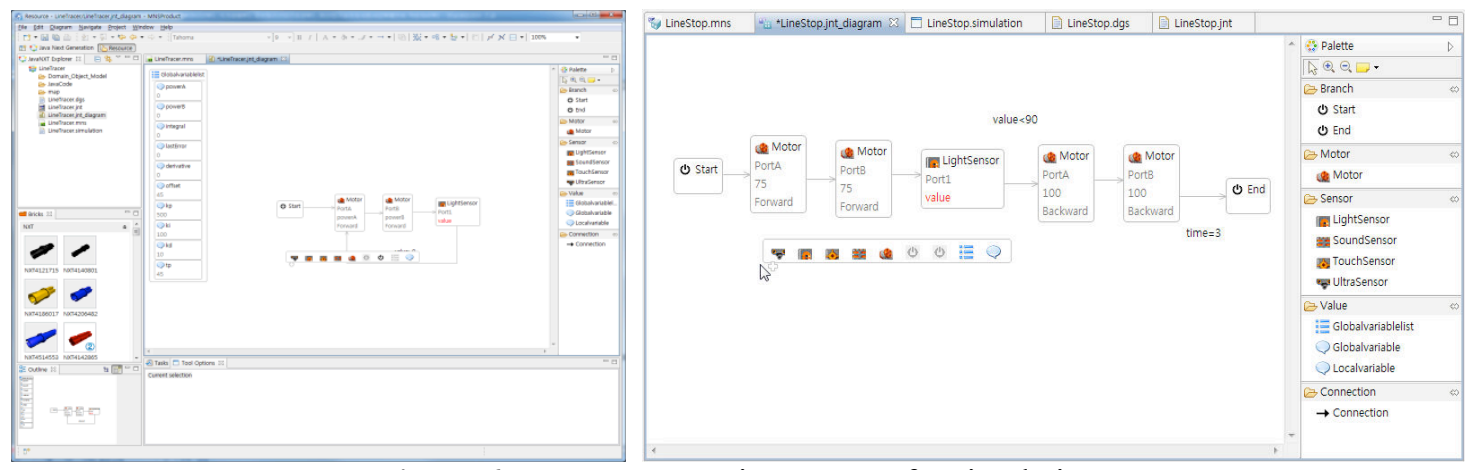

Figure 6. VPL programming process for simulation

Figure 6 shows a VPL (Visual Programming Language) programming example for a modeled robot. Instead of using complex programming structure, components for robot's major parts are provided. This reduces burden to learn VPL programming language itself, which allows a learner to focus on the robot's functions. With the reduced burden, anyone without any programming background can develop convergent thinking on scientific principles because describing robot's functions requires lots of mathematical algorithms and complex logics. Visual Programming Language is an application development environment designed on a graphical dataflow-based programming model. Rather than series of imperative commands sequentially executed, a dataflow program is more like a series of workers on an assembly line, who do their assigned task as the materials arrive. As a result VPL is well suited to programming a variety of concurrent or distributed processing scenarios. VPL is targeted for beginner programmers with a basic understanding of concepts like variables and logic. However, VPL is not limited to novices. The programming language may appeal to more advanced programmers for rapid prototyping or code development. As a result, VPL may appeal to a wide audience of users including students, enthusiasts/hobbyists, as well as possibly web developers and professional programmers. A VPL dataflow consists of a connected sequence of activities represented as blocks with inputs and outputs that can be connected to other activity blocks.

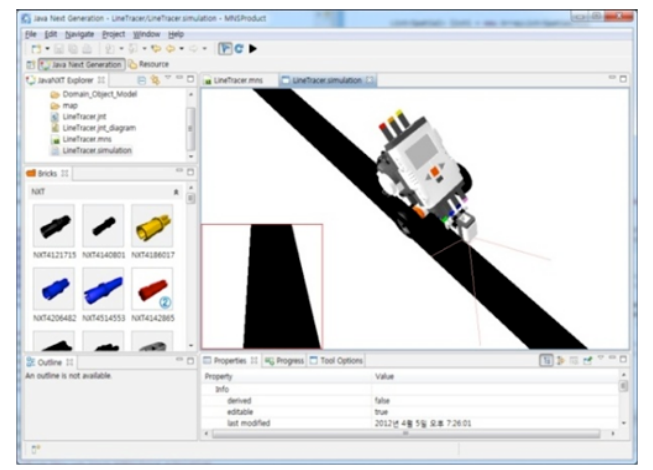

Figure 7. Robot Simulation

Figure 7 shows how a learner can perform simulation in $\mathrm{M} \& S$ platform. Throughout various simulations, the learner can see the model works as required and check any issues in the model. The robotics simulator can refer to several different robotics simulation applications. For example, in mobile robotics applications, behavior-based robotics 


\section{Issues in Information Systems \\ Volume 14, Issue 2, pp.225-232, 2013}

simulators allow users to create simple worlds of rigid objects and light sources and to program robots to interact with these worlds. The simulator allows for robotics programs to be conveniently written and debugged off-line with the final version of the program tested on an actual robot. Of course, this primarily holds for industrial robotic applications only, since the success of off-line programming depends on how similar the real environment of the robot is to the simulated environment. Sensor-based robot actions are much more difficult to simulate and/or to program off-line, since the robot motion depends on the instantaneous sensor readings in the real world.

\section{RESULTS}

We performed experiment on the education effect and satisfaction of 3D simulation-based M\&S education platform process presented in this paper. For the experiment, students in middle school and high school are selected. When it comes to the students in middle school, we choose 45 students enrolled in ICT(Information \& Communication Technology) genius class that a state government runs. As for the high school students, 45 students were selected.

Table 1 summarizes the experimental results in terms of type of students, number of people, education hours, and education subject. Students from middle school designed a driving based robot on their own creative idea and programmed if following the guideline of 3D simulation-based M\&S education process. In contrast, students from high school, is given they developed a robot arm by following the M\&S learning analysis step.

Table 1. Education Process Comparison on Learners

\begin{tabular}{|c|c|c|c|}
\hline Type of Students & $\begin{array}{c}\text { Number of } \\
\text { Students }\end{array}$ & Hours & Education Topic \\
\hline \hline $\begin{array}{c}\text { Middle School } \\
\text { (14-16 years old) }\end{array}$ & 45 & $\begin{array}{c}32 \text { hours } \\
\text { (Education + Practice) }\end{array}$ & $\begin{array}{c}\text { Driving Robot Modeling \& } \\
\text { Simulation }\end{array}$ \\
\hline $\begin{array}{c}\text { High School } \\
\text { (17-19 years old) }\end{array}$ & 40 & $\begin{array}{c}32 \text { hours } \\
\text { (Education + Practice) }\end{array}$ & $\begin{array}{c}\text { Robot Arm Modeling \& } \\
\text { Simulation }\end{array}$ \\
\hline
\end{tabular}

Figure 8 explains results of students' satisfaction and usefulness on the education effect after 3D simulation-based M\&S education process. As shown in the figure, over $90 \%$ of the students got very satisfied with the M\&S study and the M\&S education platform can be applicable to middle and high levels of students. Of this study is to investigate statistical methods were analyzed with reference to the Likert scale. A Likert scale is a psychometric scale commonly involved in research that employs questionnaires [21]. It is the most widely used approach to scaling responses in survey research. A Likert item is simply a statement that the respondent is asked to evaluate according to any kind of subjective or objective criteria; generally the level of agreement or disagreement is measured [22].

\begin{tabular}{l|c|c|c|c|c|}
\hline \multicolumn{2}{c}{ Results of middle school students' satisfaction and usefulness } \\
\hline & $\begin{array}{l}\text { strongly } \\
\text { agree(5) }\end{array}$ & agree(4) & neutral(3) & disagree(2) & $\begin{array}{c}\text { strongly } \\
\text { disagree(1) }\end{array}$ \\
\hline \hline satisfaction & $91.11 \%$ & $6.67 \%$ & $2.22 \%$ & $0.00 \%$ & $0.00 \%$ \\
\hline usefulness & $84.44 \%$ & $11.11 \%$ & $2.22 \%$ & $2.22 \%$ & $0.00 \%$ \\
\hline
\end{tabular}

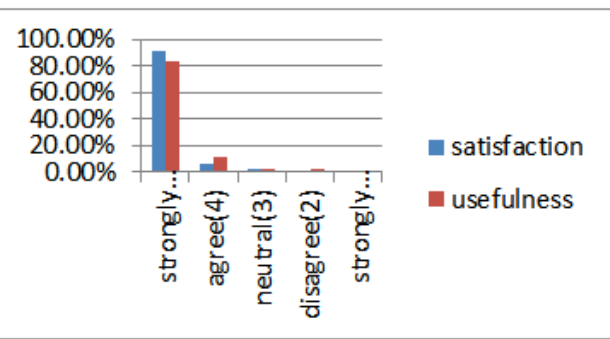

Results of high school students' satisfaction and usefulness

\begin{tabular}{l|c|c|c|c|c}
\hline & $\begin{array}{l}\text { strongly } \\
\text { agree(5) }\end{array}$ & agree(4) & neutral(3) & disagree(2) & $\begin{array}{c}\text { strongly } \\
\text { disagree(1) }\end{array}$ \\
\hline \hline satisfaction & $92.50 \%$ & $2.50 \%$ & $5.00 \%$ & $0.00 \%$ & $0.00 \%$ \\
\hline usefulness & $82.50 \%$ & $2.50 \%$ & $10.00 \%$ & $5.00 \%$ & $0.00 \%$ \\
\hline
\end{tabular}

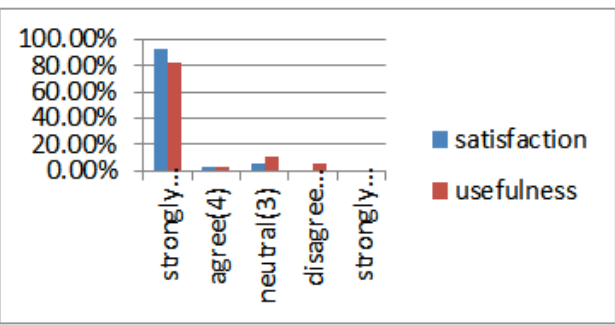

Figure 8. Results of students' satisfaction and usefulness 


\section{Issues in Information Systems}

Volume 14, Issue 2, pp.225-232, 2013

\section{CONCLUSIONS}

In this paper, 3D simulation-based M\&S education platform is introduced for smart learning. The platform proposes learner-oriented didactics by utilizing a virtual robot. The platform can improve creativity and convergent thinking. In addition, it is effective in enhancing creative problem solving ability. Next step for our research is to perform further investigation on learner's learning pattern and study how to use the pattern for smart learning.

\section{ACKNOWLEDGEMENTS}

This work was supported by the Korean Government IT R\&D program of MKE/KEIT. [10035166, Development of Intelligent Tutoring System for Nursing Creative HR]

\section{REFERENCES}

1. Treffinger, Donald J., and Scott G. Isaksen. (2005). Creative problem solving: The history, development, and implications for gifted education and talent development. Gifted Child Quarterly 49.4. 342-353.

2. Kuenzi, J., Matthews, C., and Mangan, B. (2006). Science, Technology, Engineering, and Mathematics (STEM) Education Issues and Legislative Options. Congressional Research Report. Washington, DC: Congressional Research Service.

3. Goergette Yakman.(2008). STEAM Education: an overview of creating a model of integrative education. 335358. Available: www.iteea.org/Conference/PATT/PATT19/Yakmanfinal19.pdf

4. LaPorte, J. \& Sanders, M. (1995). Technology, science, mathematics integration. In E. Martin (Ed.), Foundations of technology education: Yearbook \#44 of the council on technology teacher education. Peoria, IL: Glencoe/McGraw-Hill.

5. Sanders, M. (2006). A rationale for new approaches to STEM education and STEM education graduate programs. Paper presented at the 93rd Mississippi Valley Technology Teacher Education Conference, Nashville, TN.

6. SeongYong Hong. (2012). A Study of STEAM Education Model for Collective Intelligence Learner With Regards to Developing People of Interdisciplinary Abilities. The 37th KIPS Spring Conference, Vol.19, No.1, 1406-1409.

7. SeongYong Hong. (2012). A Study on STEAM Education using MSRDS Platform. The Korean Association of Information Education Research Journal, Vol.4, No.1, 145-151.

8. Ruth Wilson, Monica Landoni, Forbes Gibb. (2003). The WEB Book experiments in electronic textbook design. Journal of Documentation, Vol. 59 Iss: 4, $454-477$.

9. Caudell, T.P., and Mizell, D.W.(1992). Augmented Reality: an application of heads-up display technology to manual manufacturing processes. In Proceedings of the Twenty-Fifth Hawaii International Conference on Systems Science, Kauai, Hawaii, 7th-10th, Vol. 2, 659-669.

10. Liarokapis, F., Petridis, P., Lister, P. F., \& White, M. (2002). Multimedia augmented reality interface for elearning (MARIE). World Transactions on Engineering and Technology Education, 1(2), 173-176.

11. Tang, T.Y., McCalla, G.(2003). Smart recommendation for an evolving e-learning system. 11th International conference on artificial intelligence in education, Sydney, Australia, 699-710.

12. Aimeur, E. and Frasson, C.(1996). Analyzing a new learning strategy according to different knowledge levels. Computers in education, Vol 27, No. 2, 115-127.

13. Cheng, Z., Sun, S., Kansen, M., Huang, T., \& He, A.(2005). A personalized ubiquitous education support environment by comparing learning instructional requirement with learner's behavior. Proceedings of the 19th IEEE International Conference on Advanced Information Networking and Applications. 567-573.

14. K. Johns and T. Taylor. (2008). Professional Microsoft Robotics Developer Studio, Wiley Publishing Inc.

15. SeongYong Hong. (2010). Learning Method using RDS for Creative Problem Solving. Journal of KIISE: Computing Practices and Letters, Volume 16, Number 11, 1126-1130.

16. Yimin, Chen, et al. (2002). A robot simulation, monitoring and control system based on network and Java3D. Intelligent Control and Automation, 2002 Proceedings of the 4th World Congress on. Vol. 1. IEEE.

17. L. Hugues and N. Bredeche.(2006). Simbad: an autonomous robot simulation package for education and research. In Proceedings of the Ninth International Conference on the Simulation of Adaptive Behavior (SAB'06), Rome, Italy. 


\section{Issues in Information Systems}

Volume 14, Issue 2, pp.225-232, 2013

18. T. Braunl, H. Stolz.(1997). Mobile Robot Simulation with Sonar Sensors and Cameras. Simulation, vol. 69, no. 5, Nov, 277-282(6).

19. Seongyong Hong, Yong-Hyun Hwang.(2012). A Study on SMART Curriculum Utilizing Intelligent Robot Simulation. Issues in Information Systems, IACIS 2012, Volume 13, Issue 2, 131-137.

20. B. S. Fagin and L. S. Merkle.(2003). Measuring the effectiveness of robots in teaching computer science. ACM SIGCSE Bulletin, Proceedings of the 34th SIGCSE technical symposium on Computer science education, Vol.35 No.1, 307-311.

21. Carifio, James and Rocco J. Perla. (2007). Ten Common Misunderstandings, Misconceptions, Persistent Myths and Urban Legends about Likert Scales and Likert Response Formats and their Antidotes. Journal of Social Sciences 3 (3), 106-116.

22. Clason, Dennis L., and Thomas J. Dormody.(1994). Analyzing data measured by individual Likert-type items. Journal of Agricultural Education, Volum 35, No 4.31-35. 